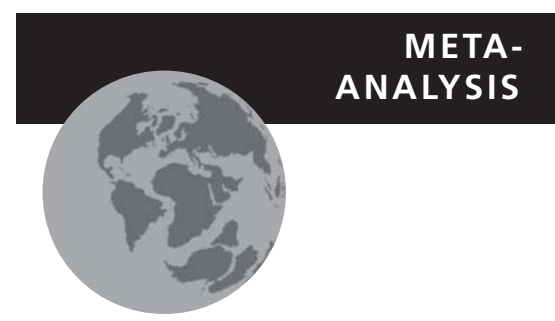

\title{
The sign and magnitude of tree-grass interaction along a global environmental gradient
}

\author{
Noemí Mazía ${ }^{1 \star}$, Jaime Moyano ${ }^{1,2}$, Luis Perez ${ }^{3}$, Sebastián Aguiar ${ }^{3}$, \\ Lucas A. Garibaldi ${ }^{4}$ and Tomas Schlichter ${ }^{1}$
}

${ }^{1}$ Departamento de Producción Vegetal, Facultad de Agronomía, Universidad de Buenos Aires, Av. San Martín 4453, Buenos Aires 1417, Argentina, ${ }^{2}$ Instituto de Investigaciónes en Biodiversidad y Medio Ambiente (INIBIOMA), Universidad Nacional del Comahue, Consejo Nacional de Investigaciones Científicas y Técnicas (CONICET), Quintral 1250, San Carlos de Bariloche, Río Negro 8400, Argentina, ${ }^{3}$ IFEVA-CONICET and Facultad de Agronomía, Universidad de Buenos Aires, Av. San Martín 4453, Buenos Aires, 1417, Argentina, ${ }^{4}$ Instituto de Investigaciones en Recursos Naturales, Agroecología y Desarrollo Rural (IRNAD), Sede Andina, Universidad Nacional de Río Negro (UNRN) - Consejo Nacional de Investigaciones Científicas y Técnicas (CONICET), Mitre 630, CP 8400, San Carlos de Bariloche, Río Negro, Argentina

*Correspondence: Noemi Mazía, Departamento de Producción Vegetal, Facultad de Agronomía, Universidad de Buenos Aires, Av. San Martín 4453, Buenos Aires 1417, Argentina.

E-mail: cmazia@agro.uba.ar

\section{ABSTRACT}

Aim The ecological literature posits that positive interactions are preponderant in stressful environments; however, the net balance between positive and negative interactions at the community level is still under debate. This study analysed the effect of trees on grass biomass in natural and cultivated woody systems distributed along a global aridity index (AI) gradient.

\section{Location Global.}

Methods We conducted a meta-analysis including eight natural biomes and tree plantations distributed in five continents. The final database consisted of 93 data pairs across 65 locations spanning a gradient from $\mathrm{AI}=0.1$ to $\mathrm{AI}=2.1$, which covered annual precipitation ranging from 70 to $3500 \mathrm{~mm}$. Effect size was calculated as the difference between above-ground grass biomass beneath and outside the tree canopy. We built linear models to evaluate the importance of different biotic and abiotic variables as potential drivers of the effect size. Multimodel inference, based on the Akaike information criterion (AICc) was used to select the best models.

Results The whole data set shows a shift from net facilitation to net competition along an increasing AI gradient. AI had the highest relative importance in explaining the sign and magnitude of the effect size. Tree characteristics (deciduous-evergreen and leguminous-non-leguminous) were the other predictive variables consistently included in almost all the 10 best models. Deciduous and leguminous trees enhanced grass biomass growing beneath them. Increasing soil sand content, $\mathrm{C} 4$ grasses and tropical and natural systems all increased the biomass of grasses growing beneath trees, but their relative importance was substantially lower than that of the AI and tree characteristics.

Main conclusions The results of our global meta-analysis showed that climatic context and the characteristics of benefactor trees both represent the main drivers of the sign and magnitude of tree-grass interactions. These findings may contribute to advancing knowledge of the mechanisms behind the global patterns.

\section{Keywords}

Aridity index, competition, facilitation, grass biomass, meta-analysis, plant interactions. 


\section{INTRODUCTION}

Coexistence of trees and grass occurs from arid scrublands to moist tropical forests. Across such a broad environmental gradient the net balance of this interaction can range from positive to negative or even neutral, although a general pattern has remained elusive. Several factors have been suggested to shape the sign of this interaction, such as climate and soil conditions, human activities, disturbance regimes, characteristics of the interacting species and also tree height, among others (Scholes \& Archer, 1997; House et al., 2003; Bucini \& Hanan, 2007; Bond \& Midgley, 2012; Moustakas et al., 2013; Rivest et al., 2013; Soliveres \& Maestre, 2014). Most studies focusing on this topic have been conducted in savannas (Belsky, 1994; Mordelet \& Menaut, 1995; Sankaran et al., 2005; Bond, 2008). Some recent works have reported a shift from competitive to facilitative tree-grass interactions along a decreasing gradient of precipitation and between $\mathrm{N}$-fixing and non-N-fixing trees (Blaser et al., 2013; Dohn et al., 2013; Moustakas et al., 2013). However, in order to build a general model of tree-grass interactions it is necessary to incorporate other natural and cultivated woody ecosystems with different structure and functioning. For this reason, in this study we include different natural biomes distributed along a broad gradient of water availability and also tree plantations. This agroecosystem was included because the cultivated area is increasing world-wide to provide fibre and wood. As a consequence, it would be important to know to what extent treegrass interactions in cultivated and natural systems may differ from each other.

Ecological communities are structured by interactions among organisms. The final outcome between positive and negative interactions allows us to quantify the preponderance of facilitation or competition at the community scale (Brooker \& Callaghan, 1998; Brooker et al., 2005). Classical ecological literature posits that positive interactions (net facilitation) tend to increase in stressful environments (Bertness \& Callaway, 1994; Brooker \& Callaghan, 1998; He \& Bertness, 2014). It has also been suggested that positive interactions could expand the range of conditions in which an organism might survive, although not grow and reproduce. Therefore, facilitation would be the dominant interaction when abiotic stress is not extreme (Holmgren \& Scheffer, 2010). While it is recognized that positive interactions play an important role in ecological communities (Stachowicz, 2001; Bruno et al., 2003), no consensus has yet been reached about the net balance of positive and negative interactions along wide gradients of environmental stress. This reflects the difficulty in scaling up to the community level, mainly because each species has a particular response to abiotic conditions and also to the local conditions imposed by the presence of different neighbours (Soliveres \& Maestre, 2014).

Along broad environmental gradients, tree cover ranges from scattered trees in savannas to scarce grasses in closed forests. Such changes in woody-grass proportions are generally associated with changes in mean annual precipitation (MAP) and soil conditions, both setting an upper limit on tree abundance (Scholes \& Archer, 1997; Bond, 2008). For example, in African savannas tree cover increases linearly along a gradient of precipitation of up to $650 \mathrm{~mm}$, above which closed woodlands develop (Sankaran et al., 2005). As a consequence, the final balance of woody-grass interaction might shift from positive to negative along a precipitation gradient, which also implies a gradient of tree abundance and/or tree cover (Murphy \& Lugo, 1986). In addition, soil texture has also been invoked as a factor influencing the final balance of tree-grass interaction in savannas (Bond, 2008; Dohn et al., 2013). In general, the positive effect of trees could be lower in fine rather than coarse soil textures given the low capacity of coarse soils to retain nutrients, which could be enhanced by adding litter biomass (Jobbágy \& Jackson, 2000). In this context, trees could enhance the availability of water for grasses growing beneath them by increasing soil organic matter and reducing evaporative demand.

The structural and functional traits of herbaceous and woody plants may also influence the net balance of tree-grass interaction. In particular, it is not clear what the net effect of trees could be in communities with preponderance of $\mathrm{C} 4$ grasses. In one way these communities could be more affected by the shade cast by trees than communities dominated by $\mathrm{C} 3$ grasses because of their higher intolerance to light reduction (Long, 1999; Sage et al., 1999; Keeley \& Rundel, 2003). Alternatively, in stressful environments, the effect of trees on C4 grass biomass could be positive, due to the amelioration of abiotic conditions (Scholes \& Archer, 1997).Tree characteristics may also play a role in shaping the sign and magnitude of tree-grass interaction. Nutrient enrichment under trees has been reported as one of the positive effects of leguminous trees and shrubs on herbaceous biomass in stressful environments (Belsky, 1994; Pugnaire et al., 1996; Scholes \& Archer, 1997; Ludwig et al., 2004). In addition it was recently demonstrated that in stressful environments deciduous trees enhanced the absorption of nitrogen by grasses growing beneath them, and also increased mineralization of organic matter (Gargaglione et al., 2014). Other results showed a reduction in grass productivity (Bahamonde et al., 2012) under deciduous trees as well as under an evergreen canopy (Rivest et al., 2013). Overall, a global model of woody-grass interactions should incorporate the main characteristics of both trees and grasses.

To evaluate the net effect (sign and magnitude) of trees on grass biomass growing beneath tree canopies we conducted a global-scale meta-analysis. The study included natural and cultivated woody systems distributed across all continents. Studies were ordered along an axis of aridity index (AI), which is a proxy for water availability (Trabucco et al., 2008). The AI is the ratio between MAP and potential evapotranspiration (PET). This index represents a more sensitive proxy of environmental stress than precipitation since it also includes atmospheric water demand, a better approximation to hydric balance (Knapp \& Smith, 2001). The objectives of 
this study were: (1) to evaluate the net effect of trees on grass biomass along a gradient of water availability and (2) to quantify how the net effect of trees varies along a gradient of soil sand content, type of woody system (plantation-natural) and characteristic of grasses (C3-C4) and trees (deciduousevergreen, and leguminous-non-leguminous). By using the net effect, we recognized that positive (facilitation) and negative (competition) interactions are operating simultaneously, and the balance between them will determine the preponderance of positive or negative interaction within a community and the final grass biomass growing beneath trees (Holzapfel \& Mahall, 1999).

We postulate the following hypothesis: (1) along a broad gradient of $\mathrm{AI}$, the sign of tree-grass interaction shifts from positive (i.e. net facilitation) to negative (i.e. net competition) as water availability increases; (2) tree characteristics (leaf longevity and $\mathrm{N}$-fixation capacity) both modify grass biomass growing under trees; (3) grass characteristics (C3-C4) are differentially affected by the shade cast by trees because of their differences in tolerance to light reduction; (4) tree plantations have a negative effect on grass biomass because they represent a selected pool of fast-growing and highly competitive trees species, compared to natural systems.

\section{MATERIALS AND METHODS}

\section{The database}

In order to compare the influence of tree cover on grass productivity, we performed a meta-analysis using the Scopus database. Our search covered a period of 26 years (from 1990 to 2015) and included the following keywords: 'pasture productivity under trees', 'silvopastoral systems', 'grassland tree facilitation', 'herbaceous under trees', 'forest pastures', 'grass-tree interaction', 'grass diversity-productivity trees'. From the 98 studies examined only 47 (see Table S1 in the Supporting Information) met the following requirements: (1) above-ground grass productivity or biomass was measured under tree shade and in open grassland within the same site (data pairs), (2) statistical information (i.e. mean values, measures of error and number of replicates) either in graphs, text or tables was provided. Those articles that did not provide control treatments were not included since comparisons were not possible. Data available in graphs were digitized using GetData Graph Digitizer 2.24. Standard error (SE) values were converted to standard deviation from the product of SE and the square root of the number of replicates. When an article provided more than one data pair we considered only independent data pairs coming from different sites in order to avoid pseudoreplication. The final database obtained (from 47 studies published during the last 26 years) consisted of 93 data pairs distributed across 65 sites (Table S1).

For each data pair we calculated the $\mathrm{AI}$ as the ratio between MAP and PET (UNEP 1997), based on data from Trabucco et al. (2008). A regression analysis was made between precipitation data reported by Trabucco et al. (2008) and those reported in the original papers. This analysis showed a coefficient of determination of 0.83 . There was only one outlier, which was located in a mountainous zone where the interpolation between meteorological stations was not accurate. Data for grass biomass came from eight biomes: tropical and subtropical grasslands savannas and shrublands, temperate grasslands savannas and shrublands, mediterranean forests woodlands and scrub, temperate broadleaf and mixed forests, tropical and subtropical moist broadleaf forests, tropical and subtropical dry broadleaf forests, deserts and xeric shrublands and montane grasslands (Olson et al., 2001). In the case of tree plantations the biomass represents the original vegetation removed.

Effect size was calculated for each data pair and represented the difference between above-ground grass productivity beneath trees $\left(X_{\mathrm{b}}\right)$ and outside the tree canopy $\left(X_{\mathrm{o}}\right)$. A positive effect size indicates higher grass productivity beneath trees with respect to outside the tree canopy, while a negative effect size means higher productivity outside the tree canopy than under trees. Therefore, when the effect size is positive the dominant interaction is facilitation, whereas if the effect size is negative the dominant interaction is competition.

We built linear models to evaluate the importance of different predictive variables as the potential drivers of effect size. AI, percentage of soil sand and latitude were employed as continuous variables. The characteristics of grasses (C3-C4) and trees (leaf longevity, deciduous-evergreen; Nfixation, leguminous-non-leguminous) and type of system (plantation-natural) were included in the model as categorical variables (Table S1). For the classification into categories of grasses (C3-C4), we considered the dominant form within each community. Soil sand content was obtained from Hengl et al. (2014) through ISRIC/WDC-Soils. For each site we extracted the percentage of sand and calculated the weighted average for all the depths in the first $30 \mathrm{~cm}$, where the highest grass root density is found (Jackson et al., 1996). For the other explanatory variables we obtained data from informed values in each publication.

\section{Data analysis}

The meta-analysis was carried out using Metawin 2.0 (Rosenberg et al., 2000). Effect sizes were measured using Hedges' $d$ instead of a log-response ratio because it is not biased by small sample sizes (Rosenberg et al., 2000). Hedges' $d$ was calculated as

$d=\frac{X_{\mathrm{b}}-X_{\mathrm{o}}}{S} \times J$

where $X_{\mathrm{b}}$ and $X_{\mathrm{o}}$ are as defined above, $S$ is the pooled standard deviation and $J$ is a correction factor accounting for a small sample size (Rosenberg et al., 2000) (see Table S3 for an example calculation). Effect sizes were calculated for the whole data set (main effect, $n=93$ ) and also for each category previously defined.

To quantify the importance of all predictive variables, we used linear models ( $\mathrm{lm}$ function in $\mathrm{R}$ software v.3.1.3) 


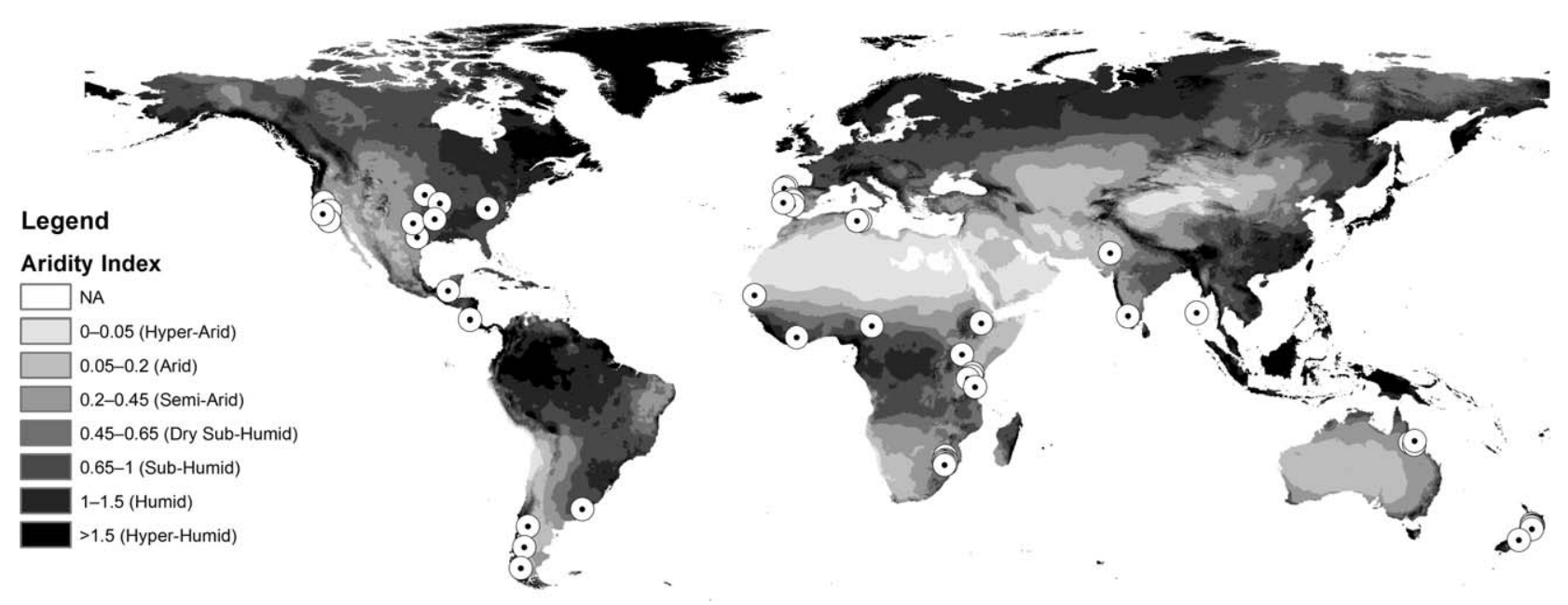

Figure 1 Global distribution of all studies included in the meta-analysis (black circles), the aridity index (mean annual precipitation/ potential evapotranspiration) increases from lighter to darker tones of grey, which implies a decreasing level of environmental stress.

(Wilkinson \& Rogers, 1973; Chambers \& Hastie, 1991; R Development Core Team, 2015). First, we tested the independence of all predictor variables through multicollinearity, based on the variance inflation factor (VIF) (Car package, VIF function) (Fox \& Weisberg, 2010). Since none of the variables showed multicollinearity (all VIF values were below 3 ), we incorporated all of them in the models. Since we were especially concerned to examine to what extent AI might modify the effect of each predictor variable, pair interactions were also incorporated (each predictor variable with the AI). We tested the model for error independence, normal distribution and homoscedasticity. These assumptions were valid in all cases. Then we performed multimodel inference based on the Akaike information criterion (AICc). AICc values were obtained based on maximum-likelihood estimates of regression coefficients (MuMIn package, dredge function). Finally, to quantify the relative importance of the different predictive variables we summed the Akaike weights for each predictor in all the models. According to this criterion, a bigger sum corresponds to a more important variable relative to the other variables that occurred in the same model.

\section{RESULTS}

The 93 data pairs distributed across 65 sites encompassed eight biomes in five continents: 24 in America (4 in South America), 6 in Europe, 47 in Africa, 6 in Asia and 10 in Oceania (Fig. 1). There were 74 data pairs in native ecosystems and 19 data pairs in plantations (Table S1). The sites spanned a wide range of environmental conditions, from an annual average temperature of 4.5 to $27.5{ }^{\circ} \mathrm{C}$ and MAP from 70 to $3500 \mathrm{~mm}$, which resulted in a range of AI from 0.11 to 2.13 (from arid to hyper-humid). The whole data set shows a shift from net facilitation to net competition (from a positive to a negative effect size) along the increasing gradient of AI (Fig. 2).
From all possible combinations among the predictor variables and the interactions between each one and the AI, we selected the 10 best models. All these models consistently included the AI and tree characteristics as the main predictors of the effect size (Table 1). However, the AI showed the highest relative importance among all predictive variables included in the models (Fig. 5). Leaf longevity and N-fixing trees were included in all and $90 \%$ of the best models, respectively (Table 1). Deciduous trees increased grass biomass (positive effect size) growing beneath them, whereas evergreen trees had a neutral effect (Fig. 4). Leguminous trees increased grass biomass across a longer portion of the AI gradient than non-leguminous trees; such interaction was included in 8 out of the best 10 models (Fig. 2, Table 1).

Soil sand content was included in 4 of the best 10 models, whereas latitude and $\mathrm{C} 3-\mathrm{C} 4$ grasses were included in 2 of the best 10 models (Table 1). These variables had a minor

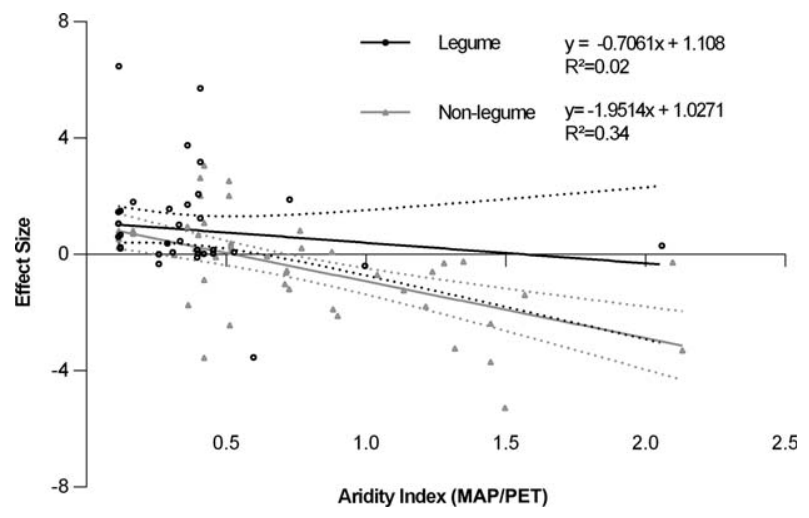

Figure 2 Relationship between effect size (above-ground herbaceous productivity beneath and outside tree canopy) and aridity index (mean annual precipitation/potential evapotranspiration, MAP/PET) for leguminous trees (black circles) and non-leguminous trees (grey triangles). Dashed lines denote the $95 \%$ confidence interval. 
Positive and negative interactions along an aridity index gradient

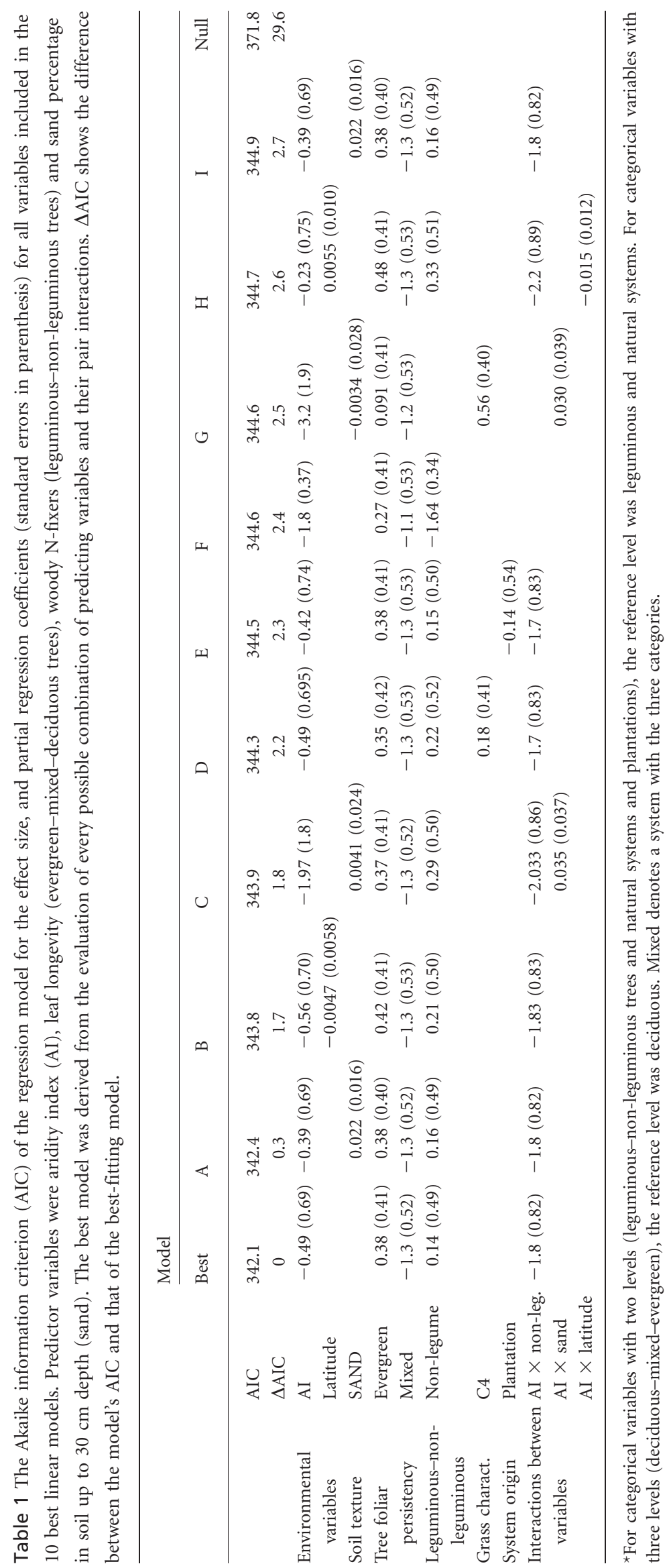


a
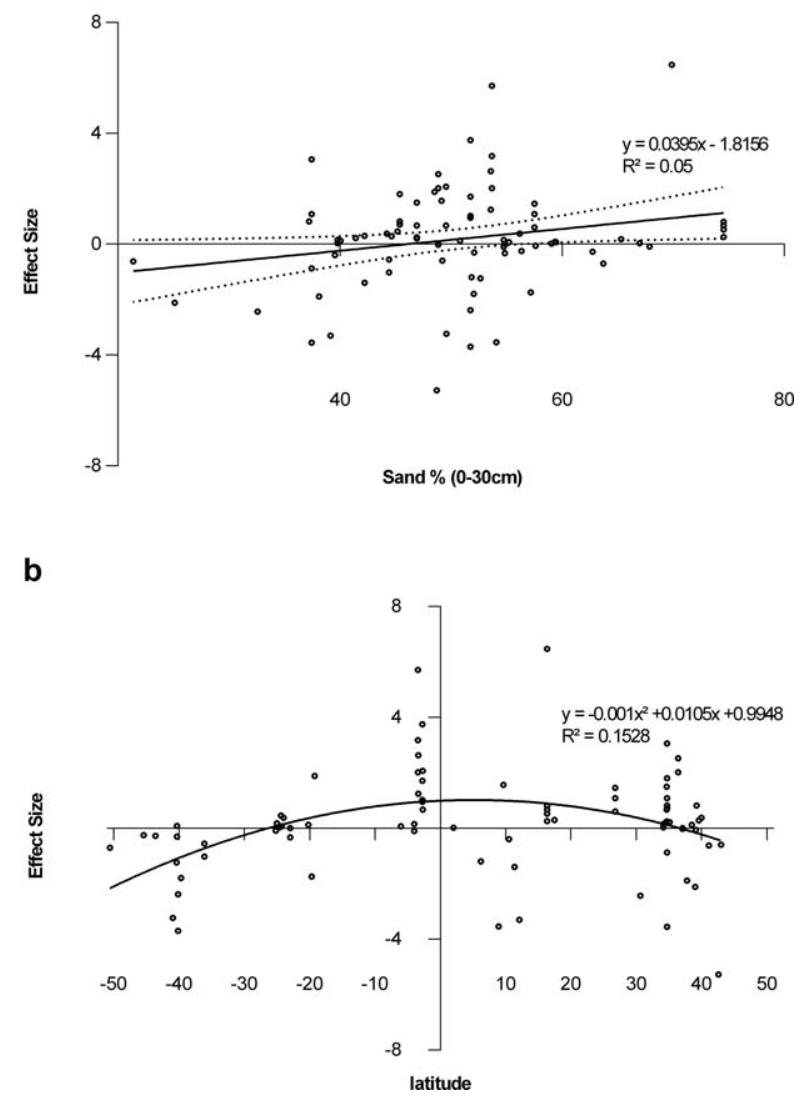

Figure 3 Relationship between effect size (above-ground herbaceous productivity beneath and outside the tree canopy) according to (a) percentage of sand in the soil (0-30 cm depth) (dashed lines denote the $95 \%$ confidence interval) and

(b) latitude (negative and positive values of latitude correspond to the Southern and Northern Hemisphere, respectively).

relative importance in explaining the variability of the effect size (Fig. 5). We found that along an increasing axis of soil sand content the effect size changed from negative to positive (Fig. 3). In general C3 grasses were negatively affected by trees (net competition) while C4 grasses showed the opposite pattern (net facilitation; Fig. 4). Natural or cultivated systems were included in 1 of the 10 best models, showing a low relative importance (Table 1, Fig. 5). Tree plantations negatively affected grass biomass growing beneath tree canopy (Fig. 4). Latitude showed a quadratic response, which implied that the effect size was positive in tropical systems and tended to be negative above nearly $30^{\circ}$ latitude (Fig. 3 ).

\section{DISCUSSION}

We examined the sign and magnitude of tree-grass interaction along a global gradient of AI. Our results showed that $\mathrm{AI}$, as a proxy for water availability, was the main predictor in explaining the impact of trees on grass biomass. Net facilitation occurred from an $\mathrm{AI}$ of 0.1 to nearly 1.5, whereas net competition occurred from an AI of 0.5 to 2.0 (Fig. 2). These findings partially agree with recent studies in the savannas of a

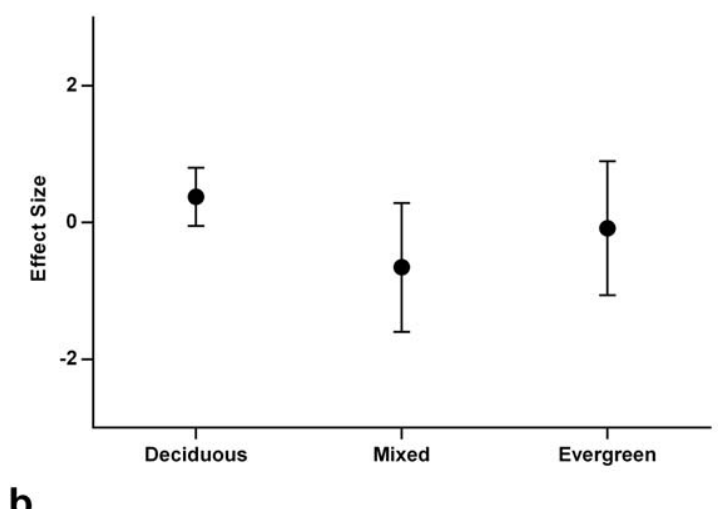

b
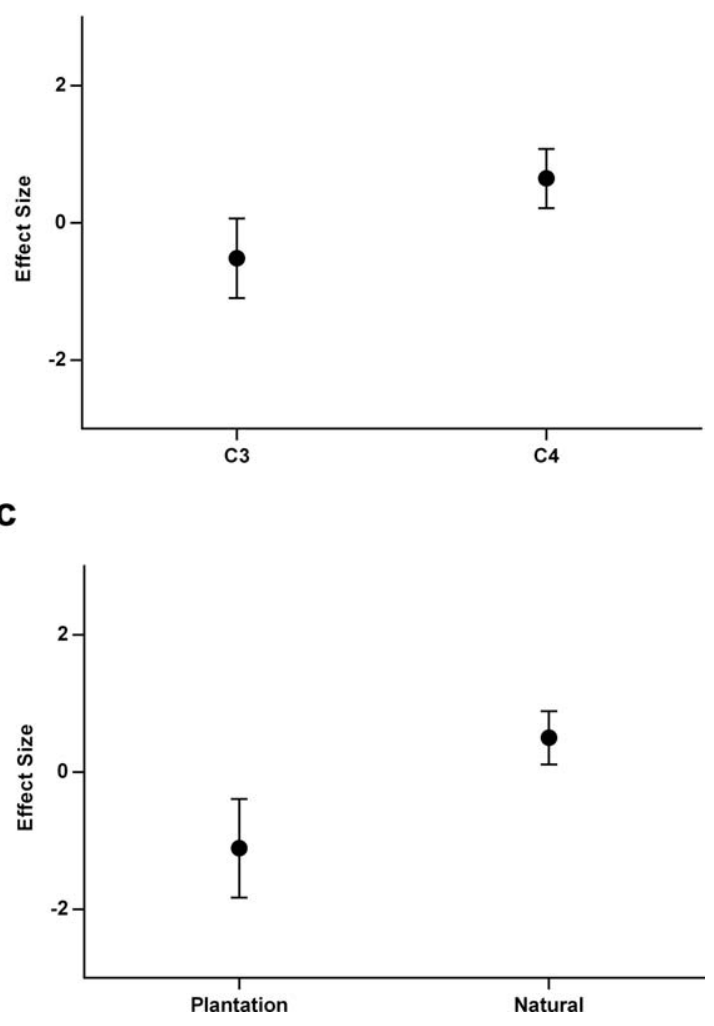

Figure 4 Effect size (above-ground herbaceous productivity beneath and outside the tree canopy) according to

(a) evergreen-mixed-deciduous trees, (b) C3-C4 grasses, and

(c) plantations-natural systems. Vertical bars for each point denote the standard error for each axis of the graph.

North America and Africa in that they found that trees enhanced grass productivity in dry environments (Blaser et al., 2013; Dohn et al., 2013; Moustakas et al., 2013). However, by using the AI as a proxy for abiotic stress, we found that the range of annual precipitation where facilitation occurred was more extended than previously reported. Our results show that facilitation extended from 70 to $1800 \mathrm{~mm}$ (cf. Dohn et al. 2013), whereas competition extended from 600 to $3500 \mathrm{~mm}$. Therefore, it seems that to employ AI at a global scale as a signal of abiotic stress could be more 


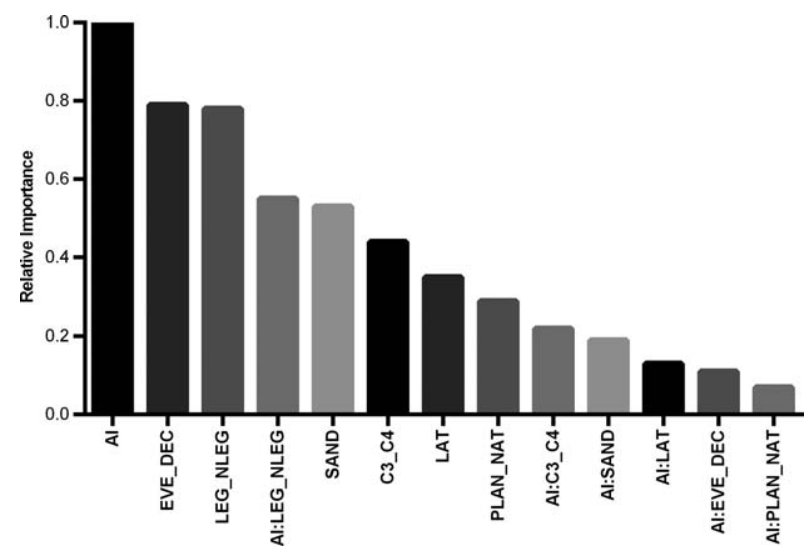

Figure 5 Relative importance of each predictor variable and the interactions between aridity index $(\mathrm{AI})$ and each predictor variable (LEG_NLEG, leguminous-non-leguminous trees; EVE_DEC: evergreen-mixed-deciduous trees; SAND, sand percentage in soil (0-30 cm depth); C3_C4, C3-C4 grasses; LAT, latitude; PLAN_NAT, plantations-natural systems). The height of each bar is the sum of the Akaike weights of all models that included the predictor of interest, taking into account the number of models in which each predictor appears.

appropriate than to employ annual precipitation. Overall, the pattern (facilitation-competition) was consistent at global scale (five continents) even including natural systems (other than savannas) and tree plantations. Interestingly, as was found by Dohn et al. (2013) within a narrow geographical context, at a global scale the effect size recorded in tropical systems was positive, whereas such effect in temperate systems in both the Northern and Southern Hemispheres was always negative (Fig. 3b).

Leaf longevity was the second most important variable in modifying the effect size, and it was independent of climatic conditions $(\mathrm{AI} \times$ leaf longevity was not included in the best models). We found that deciduous trees had a clear positive effect on grass biomass growing beneath trees, whereas the effect of evergreen trees was neutral, mainly due to its high variability (Table 1, Fig. 4a). A somewhat obvious implication regarding the role of deciduous tree cover is the increase in solar radiation during winter, which may relax competition between trees and winter grasses. In this respect, Callaway et al. (1991) measured 90\% of total radiation under deciduous trees during winter, a value that decreased to $45 \%$ by the end of spring. So water stress could be ameliorated during the spring and summer, while light competition could be reduced during the winter when hydric stress is not a limiting factor. Therefore, deciduous trees might represent the best balance between negative and positive effects of trees on grass biomass (Holmgren \& Scheffer, 2010).

Leguminous trees were also an important predictor variable in controlling the sign and magnitude of tree-grass interactions, and were included in almost all the best models. Facilitation by leguminous trees extended along a wide range of AI (0.1-1.5), whereas facilitation by non-leguminous trees occurred within a short range of AI (0.1-0.5; Fig. 2). These results agree with other studies in showing that facilitation was the dominant interaction when the benefactor was a leguminous tree whereas non-leguminous trees had a neutral or negative effect (Blaser et al., 2013; Moustakas et al., 2013). It is recognized that the presence of fertility islands beneath leguminous trees, mainly due to enhanced soil nitrogen availability, represents one of the main mechanisms involved in the positive interaction between leguminous trees and grasses in savannas (Belsky, 1994; Scholes \& Archer, 1997; Ludwig et al., 2004). Our results suggest that the extended range of facilitation by leguminous trees may be associated with a double-facilitation mechanism - the amelioration of microclimatic conditions in stressful environments and the addition of nutrients in less stressful environments (Scholes \& Archer, 1997). These double-facilitation mechanisms were globally extended and occurred along a broad axis of AI which included a range of annual precipitation from 70 to 1800 mm (cf. Blaser et al., 2013; Dohn et al., 2013; Moustakas et al. 2013). Therefore, by focusing on a global scale and also by employing $\mathrm{AI}$ as the axis of the environmental gradient, positive tree-grass interaction appears to be a more extended mechanism than has previously been reported.

Sand soil content was a low-ranked predictor variable, and was included in 4 out the best 10 models. We found that effect size increased along with soil sand content, although its effect was weaker than that of AI and tree characteristics (Fig. 5). Such a positive effect of trees might be attributed to their capacity to improve retention of water and soil nutrients in sandy soils. In contrast, Dohn et al. (2013) showed that the positive effect of trees was higher in fine than in coarse soil. It could be possible that differences in the spatial scale covered by Dohn's study and our's plays a role in the results. As a consequence, it is difficult to compare the results of both studies because the simplified model of Dohn et al. (2013) included fewer variables, possibly due to its narrow geographical context.

Interestingly, we have hypothesized that grass characteristics and the type of system (natural-plantation) could act as the main variables in explaining the effect size. Contrary to our expectation, we found that only a few models included these variables. Although our results revealed that the effect size of $\mathrm{C} 3$ was negative whereas that of $\mathrm{C} 4$ was positive, their relative importance was weak compared with $\mathrm{AI}$ and tree characteristics (Fig. 5). In addition, while we found tree plantation negatively affected grass biomass, the relative importance of the type of system was nearly three times less than that of the AI. Overall, at a global scale, the characteristics of beneficiary plants and type of system were less important than the characteristics of climatic context and benefactor trees.

The results of our study may contribute to the design of sound management decisions related to the implementation of dual-purpose systems (wood and livestock farming) in woody ecosystems. In particular, our analysis highlights the importance of trees in enhancing grass biomass in arid and 
semi-arid environments. The degradation of these ecosystems by overgrazing and wood extraction could reduce the positive tree-grass interactions. On the contrary, in less stressful environments the maintenance of a highly productive herbaceous layer could require the opening of gaps through thinning, for example with selective logging, thus reducing tree cover to relax plant competition. Finally, our results could contribute in the design of agroforestry (silvopastoral systems) by aiding the selection of the best combinations of tree and grass traits according to the abiotic conditions.

\section{CONCLUSIONS}

Tree-grass coexistence is a major concern in ecology and many studies developed in savannas have shed light on the factors shaping this interaction. However, a general model of coexistence in woody systems remains unresolved. To our knowledge, this study is the first attempt at helping to understand the main drivers in shaping tree-grass interactions world-wide and beyond savannas. Our results highlight that the sign and magnitude of tree-grass interactions are defined by a number of hierarchically ordered factors. At global scale, water availability and the characteristics of benefactor trees are consistently the main controls of the effect size.

\section{ACKNOWLEDGEMENTS}

E. Chaneton, M. Semmartin, A. Austin, H. Marrero, C. Carranza, M. Aguiar and E. Jobaggy generously helped us to improve the manuscript. The study was funded by a grant from the University of Buenos Aires to N.M. (UBACYT 2014-2017).

\section{REFERENCES}

Bahamonde, H.A., Peri, P.L., Álvarez, R. \& Barneix, A. (2012) Production and quality of grasses in a gradient of sites quality and crown covers in Nothofagus antarctica (G. Forster) Oerst. forests in Patagonia. Ecologia Austral, 22, 62-73.

Belsky, A.J. (1994) Influences of trees on savanna productivity: tests of shade, nutrients, and tree-grass competition. Ecology, 75, 922-932.

Bertness, M.D. \& Callaway, R. (1994) Positive interactions in communities. Trends in Ecology and Evolution, 9, 191-193.

Blaser, W.J., Sitters, J., Hart, S.P., Edwards, P.J. \& Olde Venterink, H. (2013) Facilitative or competitive effects of woody plants on understorey vegetation depend on $\mathrm{N}$ fixation, canopy shape and rainfall. Journal of Ecology, 101, 1598-1603.

Bond, W.J. (2008) What limits trees in C4 grasslands and savannas? Annual Review of Ecology, Evolution, and Systematics, 39, 641-659.

Bond, W.J. \& Midgley, G.F. (2012) Carbon dioxide and the uneasy interactions of trees and savannah grasses. Philosophical Transactions of the Royal Society B: Biological Sciences, 367, 601-612.
Brooker, R., Kikvidze, Z., Pugnaire, F.I., Callaway, R.M., Choler, P., Lortie, C.J. \& Michalet, R. (2005) The importance of importance. Oikos, 109, 63-70.

Brooker, R.W. \& Callaghan, T.V. (1998) The balance between positive and negative plant interactions and its relationship to environmental gradients: a model. Oikos, 81, 196-207.

Bruno, J.F., Stachowicz, J.J. \& Bertness, M.D. (2003) Inclusion of facilitation into ecological theory. Trends in Ecology and Evolution, 18, 119-125.

Bucini, G. \& Hanan, N.P. (2007) A continental-scale analysis of tree cover in African savannas. Global Ecology and Biogeography, 16, 593-605.

Callaway, R.M., Nadkarni, N.M. \& Mahall, B.E. (1991) Facilitation and interference of Quercus douglasii on understory productivity in central California. Ecology, 72, 1484-1499.

Chambers, J.M. \& Hastie, T.J. (1991) Statistical models in S. CRC Press, Inc., Boca Raton, Florida, US.

Dohn, J., Dembélé, F., Karembé, M., Moustakas, A., Amévor, K.A. \& Hanan, N.P. (2013) Tree effects on grass growth in savannas: competition, facilitation and the stress-gradient hypothesis. Journal of Ecology, 101, 202-209.

Fox, J. \& Weisberg, S. (2010) An $R$ companion to applied regression. Sage, Thousand Oaks, CA.

Gargaglione, V., Peri, P.L. \& Rubio, G. (2014) Tree-grass interactions for $\mathrm{N}$ in Nothofagus antarctica silvopastoral systems: evidence of facilitation from trees to underneath grasses. Agroforestry Systems, 88, 779-790.

He, Q. \& Bertness, M.D. (2014) Extreme stresses, niches, and positive species interactions along stress gradients. Ecology, 95, 1437-1443.

Hengl, T., de Jesus, J.M., MacMillan, R.A., Batjes, N.H., Heuvelink, G.B., Ribeiro, E., ... Gonzalez, M.R. (2014) SoilGrids $1 \mathrm{~km}$ - global soil information based on automated mapping. PLoS One, 9, e105992.

Holmgren, M. \& Scheffer, M. (2010) Strong facilitation in mild environments: the stress gradient hypothesis revisited. Journal of Ecology, 98, 1269-1275.

Holzapfel, C.A. \& Mahall, B.E. (1999) Bidirectional facilitation and interference between shrubs and annuals in the Mojave Desert. Ecology, 80, 1747-1761.

House, J.I., Archer, S., Breshears, D.D., Scholes, R.J., Coughenour, M.B., Dodd, M.B., Gignoux, J., Hall, D.O., Hanan, N.P., Joffre, R., Le Roux, X., Ludwig, J.A., Menaut, J.C., Montes, R., Parton, W.J., San Jose, J.J., Scanlan, J.C., Scurlock, J.M.O., Simioni, G. \& Thorrold, B. (2003) Conundrums in mixed woody-herbaceous plant systems. Journal of Biogeography, 30, 1763-1777.

Jackson, R.B., Canadell, J., Ehleringer, J.R., Mooney, H.A., Sala, O.E. \& Schulze, E.D. (1996) A global analysis of root distributions for terrestrial biomes. Oecologia, 108, 389-411.

Jobbágy, E.G. \& Jackson, R.B. (2000) The vertical distribution of soil organic carbon and its relation to climate and vegetation. Ecological Applications, 10, 423-436.

Keeley, J.E. \& Rundel, P.W. (2003) Evolution of CAM and C4 carbon concentrating mechanisms. International Journal of Plant Sciences, 164, S55-S77. 
Knapp, A.K. \& Smith, M.D. (2001) Variation among biomes in temporal dynamics of aboveground primary production. Science, 291, 481-484.

Long, S.P. (1999) Environmental responses. C4 plant biology (ed. by R. F. Sage and R. K. Monson), pp. 215-249. Academic Press, San Diego, CA.

Ludwig, F., De Kroon, H., Berendse, F. \& Prins, H.H.T. (2004) The influence of savanna trees on nutrient, water and light availability and the understorey vegetation. Plant Ecology, 170, 93-105.

Mordelet, P. \& Menaut, J.C. (1995) Influence of trees on above-ground production dynamics of grasses in a humid savanna. Journal of Vegetation Science, 6, 223-228.

Moustakas, A., Kunin, W.E., Cameron, T.C. \& Sankaran, M. (2013) Facilitation or competition? Tree effects on grass biomass across a precipitation gradient. PLoS One, 8, e57025.

Murphy, P.G. \& Lugo, A.E. (1986) Ecology of tropical dry forest. Annual Review of Ecology and Systematics, 17, $67-88$.

Olson, D.M., Dinerstein, E., Wikramanayake, E.D., Burgess, N.D., Powell, G.V.N., Underwood, E.C., D’amico, J.A., Itoua, I., Strand, H.E., Morrison, J.C., Loucks, C.J., Allnutt, T.F., Ricketts, T.H., Kura, Y., Lamoreux, J.F., Wettengel, W.W., Hedao, P. \& Kassem, K.R. (2001) Terrestrial ecoregions of the world: a new map of life on earth. BioScience, 51, 933-938.

Pugnaire, F.I., Haase, P. \& Puigdefábregas, J. (1996) Facilitation between higher plant species in a semiarid environment. Ecology, 77, 1420-1426.

R Development Core Team (2015) R: a language and environment for statistical computing. R Foundation for Statistical Computing, Vienna, Austria.

Rivest, D., Paquette, A., Moreno, G. \& Messier, C. (2013) A meta-analysis reveals mostly neutral influence of scattered trees on pasture yield along with some contrasted effects depending on functional groups and rainfall conditions. Agriculture, Ecosystems and Environment, 165, 74-79.

Rosenberg, M.S., Adams, D.C. \& Gurevitch, J, (2000) MetaWin: statistical software for meta-analysis: version 2.0. Sinauer Associates, Sunderland, MA.

Sage, R.F., Wedin, D.A. \& Li, M. (1999) The biogeography of C4 photosynthesis: patterns and controlling factors. C4 plant biology (ed. by R. F. Sage and R. K. Monson), pp. 313-373. Academic Press, San Diego, CA.

Sankaran, M., Hanan, N.P., Scholes, R.J., et al. (2005) Determinants of woody cover in African savannas. Nature, 438, 846-849.

Scholes, R.J. \& Archer, S.R. (1997) Tree-grass interactions in savannas. Annual Review of Ecology and Systematics, 28, $517-544$

Soliveres, S. \& Maestre, F.T. (2014) Plant-plant interactions, environmental gradients and plant diversity: a global synthesis of community-level studies. Perspectives in Plant Ecology, Evolution and Systematics, 16, 154-163.
Stachowicz, J.J. (2001) Mutualism, facilitation, and the structure of ecological communities. BioScience, 51, 235-246.

Trabucco, A., Zomer, R.J., Bossio, D.A., van Straaten, O. \& Verchot, L.V. (2008) Climate change mitigation through afforestation/reforestation: a global analysis of hydrologic impacts with four case studies. Agriculture, Ecosystems and Environment, 126, 81-97.

Wilkinson, G. \& Rogers, C. (1973) Symbolic description of factorial models for analysis of variance. Applied Statistics, 22, 392-399.

\section{SUPPORTING INFORMATION}

Additional Supporting Information may be found in the online version of this article:

Table S1 Types of biomes and characteristics of trees and grasses included in the analysis.

Table S2 Effect size, variance and aridity index of each study included in the analysis.

Table S3 Example of the calculation procedure to obtain the effect size.

\section{BIOSKETCH}

Noemí Mazía is interested in the dynamics of woodygrass interactions in grasslands and savannas, and on plant-herbivore interactions in forest ecosystems, with emphasis on the trophic and environmental controls of insect herbivory.

Author contributions: N.M., L.P. and T.S. developed the ideas and designed the research. N.M., J.M., L.P. and S.A. performed the research. J.M., L.P. and L.A.G. analysed the data. N.M. wrote the first draft, with inputs from J.M., L.P. and T.S.; all the authors contributed substantially to revising the manuscript.

Editor: Thomas Gillespie

\section{APPENDIX 1: DATA SOURCES}

Abdallah, F. \& Chaieb, M. (2010) Interactions of Acacia raddiana with herbaceous vegetation change with intensity of abiotic stress. Flora - Morphology, Distribution, Functional Ecology of Plants, 205, 738-744.

Abdallah, F., Noumi, Z., Touzard, B., Belgacem, A.O., Neffati, M. \& Chaieb, M. (2008) The influence of Acacia tortilis (Forssk.) Subsp. raddiana (Savi) and livestock grazing on grass species composition, yield and soil nutrients in arid environments of South Tunisia. Flora - Morphology, Distribution, Functional Ecology of Plants, 203, 116-125.

Abule, E., Smit, G.N. \& Snyman, H.A. (2005) The influence of woody plants and livestock grazing on grass species composition, yield and soil nutrients in the Middle Awash Valley of Ethiopia. Journal of Arid Environment, 60, 343-358

Anderson, L.J., Brumbaugh, M.S. \& Jackson, R.B. (2001) Water and tree-understory interactions: a natural experiment in a savanna with oak wilt. Ecology, 82, 33-49.

Andrade, H.J., Esquivel, H. \& Ibrahim, M. (2008) Disponibilidad de forrajes en sistemas silvopastoriles con especies arbóreas nativas en el trópico seco de Costa Rica. Zootecnia Tropical, 26, 289-292.

Awada, T., Perry, M.E.L. \& Schacht, W.H. (2003) Photosynthetic and growth responses of the C3 Bromus inermis and the C4 Andropogon gerardii to tree canopy cover. Canadian Journal of Plant Science, 83, 533-540.

Bahamonde, H.A., Peri, P.L., Álvarez, R. \& Barneix, A. (2012) Producción y calidad de gramíneas en un gradiente de calidades de sitio y coberturas en bosques de Nothofagus antarctica (G. Forster) Oerst. en Patagonia. Ecología Austral, 22, 62-73.

Belsky, A.J. (1992) Effects of trees on nutritional quality of understorey gramineous forage in tropical savannas. Tropical Grasslands, 26, 12-20.

Belsky, A.J. (1994) Influences of trees on savanna productivity: tests of shade, nutrients, and tree-grass competition. Ecology, 75, 922-932. 
Belsky, A.J., Mwonga, S.M., Amundson, R.G., Duxbury, J.M. \& Ali, A.R. (1993) Comparative effects of isolated trees on their undercanopy environments in high- and low-rainfall savannas. Journal of Applied Ecology, 30, 143-155.

Belsky, A.J., Mwonga, S.M., \& Duxbury, J.M. (1993) Effects of widely spaced trees and livestock grazing on understory environments in tropical. Agroforestry Systems, 24, 1-20.

Burner, D.M. \& Brauer, D.K. (2003) Herbage response to spacing of loblolly pine trees in a minimal management silvopasture in southeastern USA. Agroforestry Systems, 57, 69-77.

Callaway, R.M., Nadkarni, N.M. \& Mahall, B.E. (1991) Facilitation and interference of Quercus douglasii on understory productivity in central. Ecology, 72, 1484-1499.

Clavijo, M.P., Cornaglia, P.S., Gundel, P.E., Nordenstahl, M. \& Jobbagy, E.G. (2010) Limits to recruitment of tall fescue plants in poplar silvopastoral systems of the Pampas, Argentina. Agroforestry Systems, 80, 275-282.

Dubbert, M., Mosena, A., Piayda, A., Cuntz, M., Correia, A.C., Pereira, J.S. \& Werner, C. (2014) Influence of tree cover on herbaceous layer development and carbon and water fluxes in a Portuguese cork-oak woodland. Acta Oecologia, 59, 35-45.

Dube, F., Espinosa, M., Stolpe, N.B., Zagal, E., Thevathasan, N.V. \& Gordon, A.M. (2012) Productivity and carbon storage in silvopastoral systems with Pinus ponderosa and Trifolium spp., plantations and pasture on an Andisol in Patagonia, Chile. Agroforestry Systems, 86, 113-128.

Durr, P.A. \& Rangel, J. (2002) Enhanced forage production under Samanea saman in a subhumid tropical grassland. Agroforestry Systems, 54, 99-102.

Feldhake, C.M., Neel, J.P.S. \& Belesky, D.P. (2010) Establishment and production from thinned mature deciduous-forest silvopastures in Appalachia. Agroforestry Systems, 79, 3137.

Fernández, M.E., Gyenge, J., Licata, J., Schlichter, T. \& Bond, B.J. (2008) Belowground interactions for water between trees and grasses in a temperate semiarid agroforestry system. Agroforestry Systems, 74, 185-197.

Grouzis, M. \& Akpo, L.E. (1997) Influence of tree cover on herbaceous above- and belowground phytomas in the Sahelian zone of Senegal. Journal of Arid Environments, 35, 285296.

Guevara-Escobar, A., Kemp, P.D., Mackay, A.D. \& Hodgson, J. (2007) Pasture production and composition under poplar in a hill environment in New Zealand. Agroforestry Systems, 69, 199-213.

Harmand, J.M., Njiti, C.F., Bernhard-Reversat, F. \& Puig, H. (2004) Aboveground and belowground biomass, productivity and nutrient accumulation in tree improved fallows in the dry tropics of Cameroon. Forest Ecology and Management, 188, 249-265.

Hussain, Z., Kemp, P.D., Horne, D.J. \& Jaya, I.K. (2009) Pasture production under densely planted young willow and poplar in a silvopastoral system. Agroforestry Systems, 76, 351362

Jackson, J. \& Ash, A.J. (1998) Tree-grass relationships in open eucalypt woodlands of northeastern Australia: influence of trees on pasture productivity, forage quality and species distribution. Agroforestry Systems, 40, 159-176.

Jackson, L.E., Strauss, R.B., Firestone, M.K. \& Bartolome, J.W. (1990) Influence of tree canopies on grassland productivity and nitrogen dynamics in deciduous oak savanna. Agriculture, Ecosystems and Environment, 32, 89-105.

Jeddi, K. \& Chaieb, M. (2009) Using trees as a restoration tool in Tunisian arid areas: effects on understorey vegetation and soil nutrients. Rangeland Journal, 31, 377-384.

Kallenbach, R.L., Venable, E.B., Kerley, M.S. \& Bailey, N.J. (2010) Stockpiled tall fescue and livestock performance in an early stage midwest silvopasture system. Agroforestry Systems, 80, 379-384.

Kumar, B.M., George, S.J. \& Suresh, T.K. (2001) Fodder grass productivity and soil fertility changes under four grass + tree associations in Kerala, India. Agroforestry Systems, 52, 91-106.
Ludwig, F., de Kroon, H., Berendse, F. \& Prins, H.H.T. (2001) Effect of nutrients and shade on tree-grass interactions in an East African savanna. Journal of Vegetation Science, 12, 579-588.

Ludwig, F., de Kroon, H., Berendse, F. \& Prins, H.H.T. (2004) The influence of savanna trees on nutrient, water and light availability and the understorey vegetation. Plant Ecology, 170, 93-105.

Mordelet, P. \& Menaut, J.C. (1995) Influence of trees on above-ground production dynamics of grasses in a humid savanna. Journal of Vegetation Science, 6, 223-228.

Moreno, G. (2008) Response of understorey forage to multiple tree effects in Iberian dehesas. Agriculture, Ecosystems and Environment, 123, 239-244.

Mosquera-Losada, M.R., Ferreiro-Domínguez, N. \& Rigueiro-Rodríguez, A. (2010) Fertilization in pastoral and Pinus radiata D. Don silvopastoral systems developed in forest and agronomic soils of northwest Spain. Agriculture, Ecosystems and Environment, 139, 618628.

Moustakas, A., Kunin, W.E., Cameron, T.C. \& Sankaran, M. (2013) Facilitation or competition? Tree effects on grass biomass across a precipitation gradient. PLoS One, 8, e57025.

Nordenstahl, M., Gundel, P.E., Clavijo, M.P. \& Jobbágy, E.G. (2011) Forage production in natural and afforested grasslands of the Pampas: ecological complementarity and management opportunities. Agroforestry Systems, 83, 201-211.

Pandey, C.B., Verma, S.K., Dagar, J.C. \& Srivastava, R.C. (2011) Forage production and nitrogen nutrition in three grasses under coconut tree shades in the humid-tropics. Agroforestry Systems, 83, 1-12.

Peri, P.L., Lucas, R.J. \& Moot, D.J. (2007) Dry matter production, morphology and nutritive value of Dactylis glomerata growing under different light regimes. Agroforestry Systems, 70, 63-79.

Ratliff, R.D., Duncan, D.A. \& Westfall, S.E. (1991) California oak-woodland overstory species affect herbage understory: management implications. Journal of Range Management, 44, 306-310

Silva-Pando, F.J., González-Hernández, M.P., \& Rozados-Lorenzo, M.J. (2002) Pasture production in a silvopastoral system in relation with microclimate variables in the Atlantic coast of Spain. Agroforestry Systems, 56, 203-211.

Simmons, M.T., Archer, S.R., Ansley, R.J. \& Teague, W.R. (2008) Grass effects on tree (Prosopis glandulosa) growth in a temperate savanna. Journal of Arid Environments, 69, 212-227.

Simmons, M.T., Archer, S.R., Teague, W.R. \& Ansley, R.J. (2008) Tree (Prosopis glandulosa) effects on grass growth: an experimental assessment of above- and belowground interactions in a temperate savanna. Journal of Arid Environments, 72, 314-325.

Singh, G., Rathod, T.R., Mutha, S., Upadhyaya, S. \& Bala, N. (2008) Impact of different tree species canopy on diversity and productivity of understorey vegetation in Indian desert. Tropical Ecology, 49, 13-23.

Stalheber, K.A. \& D'Antonio, C.M. (2014) Do tree canopies enhance perennial grass restoration in California oak savannas? Restoration Ecology, 22, 574-581.

Treydte, A.C., Heitkönig, I.M., Prins, H.H.T. \& Ludwig, F. (2007) Trees improve grass quality for herbivores in African savannas. Perspectives in Plant Ecology, Evolution and Systematics, 8, 197-205.

Treydte, A.C., Grant, C.C. \& Jeltsch, F. (2009) Tree size and herbivory determine below-canopy grass quality and species composition in savannahs. Biodiversity and Conservation, 18 3989-4002.

Villanueva-Lopez, G., Martínez-Zurimendi, P., Casanova-Lugo, F., Ramírez-Avilés, L. \& Montañez-Escalante, P.I. (2015) Carbon storage in livestock systems with and without live fences of Gliricidia sepium in the humid tropics of Mexico. Agroforestry Systems, 89, 10831096.

Weltzin, J.F. \& Coughenour, M.B. (1990) Savanna tree influence on understory vegetation and soil nutrients in northwestern Kenya. Journal of Vegetation Science, 1, 325-334. 